\title{
Research on the Practice of "Embedded" Intelligent Pension Service -Taking Jinghua Pension Community as an Example
}

\author{
Qi Zhang ${ }^{1}$ \\ ${ }^{1}$ School of Finance and Public Administration, Harbin University of Commerce, Harbin, Heilongjiang150028, China \\ *Corresponding author. Email: www.754733783@qq.com
}

\begin{abstract} pension service in China.

\section{INTRODUCTION}

At the present stage, China's aging population is increasing, and the pension problem has become a very concerned issue. At present, China's pension is mainly family care, followed by institutional pension, but no matter which way, there need to be enough manpower to support. As China's population structure is constantly changing, the old pension model will bring huge pressure to the society. Moreover, in the existing pension model, the elderly are not active enough to participate and cannot meet the needs of the elderly.[1]Based on the above background, "embedded" pension and smart pension began to emerge. This paper combines these two pension modes, integrates and innovates the content of pension service, and constructs a new "embedded" intelligent pension service. This old-age care service model is based on the community as the carrier, embedded with advanced Internet technology, while embedding resources, functions and communication, so that the elderly can be satisfied in both material and spiritual levels.
\end{abstract}

With the aggravation of the aging population, the pension service has become an issue of great concern to people in society. With the development of science and technology and economy, the smart pension model is becoming more and more mature. Therefore, a new model of "embedded smart pension" has emerged, and some pension communities have begun to try it. However, in the process of deepening the "embedded" smart pension service model in China, there are still some problems, such as the traditional pension concept obstruction, the lack of government impetus, the low quality of embedded social resources, and the insufficient promotion of integrated social forces. This paper discusses the practice of embedded intelligent pension service in Jinghua Pension Community, analyzes the shortcomings of embedded intelligent pension service, and puts forward some feasible suggestions for the future development of embedded intelligent

Keywords: Embedded, wisdom pension, resource embedding, function embedding, embedded communication

\section{ANALYSIS OF RELATED CONCEPTS}

"Embedded" wisdom endowment as a brand new concept, mainly integrated embedded old-age pension and intelligence service content, to the community as the carrier, will endowment institutions, health care, and social forces, such as embedded into, [2] make full use of the advanced Internet technology, using intelligent platform to provide various information services for the elderly, will integrate all available resources, realize the fine development of old-age service. This paper argues that the "embedded" intelligent pension model is completely different from the traditional pension service model: it has a large number of participants, and each participant can realize information sharing under the Internet connection, and can provide targeted services for the elderly according to their individual differences.

\section{PRACTICE ANALYSIS OF "EMBEDDED"INTELLIGENT ELDERLY CARE SERVICE}

This paper intends to take the Jinghua community pension service as an example to analyze the "embedded" pension service mode. Established in 2009, Jinghua Community is located in the center of the main urban area of Harbin City. It is a community specialized in elderly care services, with a construction area of 80,000 square meters, 12 low-rise apartments, 1 sports center and 1 nursing home. Currently, more than 1300 people have moved in. Many intelligent services are provided for the elderly. 


\subsection{Analysis on Factors of Embedded Pension Service in Jinghua Community}

\subsubsection{Function embedding: life services in various forms}

When Jinghua community provides old-age care services for the elderly, it is carried out according to the principle of graded management. In view of the different needs of the elderly, Jinghua community also provides life services divided into levels for the elderly to choose. See Table 1 for the contents.

Table 1 Life service content of Jinghua community

\begin{tabular}{|c|c|}
\hline $\begin{array}{c}\text { The service } \\
\text { level }\end{array}$ & The service content \\
\hline $\begin{array}{c}\text { The primary } \\
\text { service }\end{array}$ & $\begin{array}{l}\text { 1. Help the elderly clean up and do a } \\
\text { good job of cleaning the elderly; } 2 \text {. } \\
\text { Provide entertainment services to the } \\
\text { elderly and help them exercise; } 3 \text {. Set } \\
\text { up health records for the elderly, and } \\
\text { provide health examination and } \\
\text { rehabilitation services for the elderly. }\end{array}$ \\
\hline $\begin{array}{c}\text { Intermediate } \\
\text { service }\end{array}$ & $\begin{array}{l}\text { 1. Including all contents of the primary } \\
\text { service; } 2 \text {. Personal body cleaning } \\
\text { services for the elderly; } 3 \text {. The old } \\
\text { People's Daily necessities agent; } 3 \text {. } \\
\text { Develop targeted rehabilitation plans } \\
\text { for each elderly person and cooperate } \\
\text { with them. }\end{array}$ \\
\hline Senior service & $\begin{array}{l}\text { 1. All services of intermediate service; } \\
\text { 2. Manipulating hands, feet, nails and } \\
\text { hairdressing services for the elderly; } 3 \text {. } \\
\text { Accompany the elderly in outdoor } \\
\text { activities on time; } 4 \text {. Check the } \\
\text { physical condition of the elderly on } \\
\text { time. }\end{array}$ \\
\hline Super service & $\begin{array}{l}\text { 1. All contents of the premium service; } \\
\text { 2. Comprehensive catering services for } \\
\text { the elderly; } 3 \text {. Wipe the body for the } \\
\text { elderly, dress and undress. }\end{array}$ \\
\hline
\end{tabular}

\subsubsection{Resource embedding: health services combined with medical care}

According to the health needs of the elderly, Jinghua Senior Community cooperates with medical institutions to provide combined medical and nursing services in the community. Cooperate with 8 hospitals including Harbin
First Hospital and Harbin Second Hospital to arrange physical examination and nursing. It has signed an agreement with more than $80 \%$ health institutions, and each elderly person has his own exclusive health physician who is in charge of it, which is more beneficial to understand the health status of the elderly.

\subsubsection{Communication embedding: rich and varied emotional services}

Sino view very focused to respect the development of the culture, the community within the community has set up a "respect", and regularly carry out a series of the elderly care activities, such as "one to one" activities, with "love", "the silver age and mutual assistance" activities, let old people communicate with others in the entertainment activities, meet the emotional needs of the elderly.

\subsection{Analysis of the Characteristics of the "Embedded" Intelligent Pension Service Mode in Jinghua Community}

\subsubsection{Embedding social resources into pension communities}

King Wah Community is well staffed to serve the elderly. First of all, Jinghua community has embedded social resources such as social workers and volunteers into the pension, which enriches the service content. Secondly, Jinghua community has embedded medical care institutions to establish health records for the elderly, and the combination of medical care and care has been put into practice. [3] Thirdly, Jinghua community has built a special cloud platform for elderly care services, where they can put forward their own opinions and suggestions, which meets the diverse needs of the elderly [4].

\subsubsection{Embedding smart technology into elderly care services}

In 2017, Jinghua Community built a cloud platform for comprehensive intelligent elderly care service, and input the information of all the elderly people in the community into the platform. In 2019, based on the intelligent cloud platform for comprehensive elderly services, Jinghua Community built an intelligent center for healthy elderly services, which could receive calls from elderly people at any time and immediately serve them on-demand. This realizes informatization and networking of elderly services, makes it more humane and convenient, and accelerates the scientific and intelligent statistics and services for the elderly [5]. 


\subsubsection{Virtualize the "Trinity" community concept}

Embedded smart pension service in Jinghua community has both community entity institution and network virtual service. [6] Through the combination of virtual and real, community, institution and home are integrated into one, forming a brand new pension service system. "Trinity" pension services, service personnel will be door-to-door service. Every year, the smart elderly care service platform will be used to organize volunteers to learn the elderly care knowledge and safety management knowledge. While the old volunteers are learning, the elderly can also listen to the lessons online, so that the elderly have a greater sense of belonging and happiness in the community.

\subsection{Analysis of the Existing Problems in the "Embedded" Intelligent Pension Service Mode of Jinghua Community}

\subsubsection{The embedded technology is not smart enough}

First of all, data processing technology is relatively backward. The intelligent elderly care service cloud platform established by Jinghua Community provides various services for the elderly, but the methods are relatively backward, the data analysis is not comprehensive enough, and the demand response is not timely enough. The elderly cannot get the response from the service provider immediately after submitting the demand, and the tracking management cannot be realized. Second, smart devices are not smart enough. [7] The development of embedded smart pension in Jinghua Community has just started. Compared with first-tier cities such as Shanghai and Beijing, it is still not perfect. The facilities and network system cannot be adapted to local conditions and lacks innovation.

\subsubsection{There is a conflict between security purpose and privacy requirement}

Embedded wisdom endowment of Jinghua community is carried out by relying on Internet technology. Since the Internet, there are certain risks. After the elderly stay in Jinghua Community, the community will handle a "peace of mind life card" for them, the card is the same size as the bank card, in this card, the elderly's identity information, and telephone number is recorded. These information has been leaked. In the Jinghua community, there are often calls to sell health care products to the elderly. The privacy leakage of the elderly is a concern of the Jinghua community.

\subsubsection{Economic conditions are limited}

Due to the individual differences of the elderly, their needs are also different. To meet their needs is the most important work. However, due to the limited economic conditions in Jinghua community, the types of smart pension products are not rich enough. The smart devices provided for the elderly in the community are mainly smart bracelets, smart watches, computers, etc. All they can do for the elderly is to monitor blood pressure, blood sugar, heart rate, etc., which cannot reflect the superiority of smart pension. Due to insufficient economic conditions, intelligent elderly care equipment of high-end AI technology robots has not been able to be introduced.

\section{ANALYZE THE EXISTING PROBLEMS AND COUNTERMEASURES OF THE IN- DEPTH PROMOTION OF THE "EMBEDDED" INTELLIGENT PENSION SERVICE MODEL}

\author{
4.1. Problems Existing in the In-depth \\ Promotion of "Embedded" Smart Elderly Care \\ Services
}

\subsubsection{Obstacles of traditional pension concepts}

In our country, the idea of raising children for old age has been deeply rooted in people's hearts. In the 21st century, there are still many people with this idea, and not only the elderly, the children of the elderly will also have this idea. Therefore, many people do not have a good understanding of embedded wisdom pension, or even cannot accept it. Many people think that when they are old, they can have their children around them and recuperate at home. They can eat and drink enough and take medicine when they are sick. They do not care about the spiritual needs of the elderly at all. A lot of old people, and even their children due to accept education degree is low, the pension only exist in the understanding of the concept of wisdom, does not understand its service connotation, the endowment of the technology, the embedded intelligence products and services more unknown, cannot follow the development of The Times, formed the digital divide, with embedded wisdom endowment the new mode, hindered the process of its development [8].

There are also some people who doubt the smart pension service, believing that it is impossible for others to take care of their parents better than themselves. This is because some people do not understand the embedded smart pension service at all, even when they hear of its benefits, they are afraid to try it. In addition, some people think that the cost of such high-end services as embedded intelligent pension is necessarily high, and the family economic level cannot afford it. All the above ideas are 
caused by the traditional concept of pension, and the correct understanding of intelligent pension cannot be formed, which leads to the healthy development of embedded intelligent pension.

\subsubsection{Lack of impetus from the government}

There are many aspects of embedded smart pension, which need to provide all kinds of services for the elderly. Therefore, it is necessary to cooperate with all relevant departments under the leadership of the government. Only in this way can the smart pension service work be carried out smoothly. However, the government does not have uniform policies and regulations at present, and most departments "fight alone". Due to the influence of the system and the inability to share information in time, the functions of various departments are divided. For example, in the embedded smart pension service, the health information of the elderly is in the charge of the health department, the employment of elderly service personnel is in the charge of the labor department,[9] the elderly service is in the charge of the administrative department, and all the work is under separate jurisdiction. For example, when the elderly have physical problems, their health information needs to be retrieved from the health department, the medical staff can not know the elderly's physical condition in time, delay the diagnosis of the disease, if the situation is serious, it is likely to cause an irreversible situation. This is due to the lack of government promotion, lack of attention to elderly care services, lack of systematic policy support, and lack of special funds to establish a communication platform for various departments, ultimately resulting in the communication between various departments in a timely manner.

\subsubsection{The quality of embedded social resources is not high}

The embedded social resources play an important role in the embedded intelligent pension service. However, although various social resources are embedded at present, the quality of resources is uneven.

Many community volunteers have not received professional training before they join the elderly care service, and most of them have more passion than ability, so they have a strong randomness when they perform elderly care service. This also indicates that the development of China's embedded intelligent pension service should strengthen the training of volunteers, and set the entry threshold, and show the provisions and operational requirements of volunteers in the form of legislation, so as to avoid the blindness and randomness in the pension service. In addition, there are not many volunteers who take the initiative to join the elderly care service. Moreover, the lack of professional training before joining the service leads to the prejudice of the public against volunteers and the belief that they can not play a real role. In addition, there is no unified planning and management for the activities carried out by volunteers in the smart pension community, which makes it extremely difficult to carry out the volunteer service work and fails to gain social recognition while the development is sluggish. Wisdom pension embedded in the medical resources are also facing many difficulties, in our country, endowment and medical points belong to different departments, medical resources in the process of embedded wisdom endowment, financial support is insufficient, a lot of facilities to keep up with demand, not for the elderly to provide efficient medical combining services, finally unable to obtain a good effect.

\subsubsection{Insufficient promotion of integrated social forces}

According to the theory of welfare pluralism, the supply of social welfare needs to mobilize the enthusiasm and initiative of all relevant groups, and the government, enterprises, social organizations and citizens can fully participate in order to realize the supply of social welfare. The same is true in the embedded wisdom pension. Only by fully integrating the social forces can the value be maximized, all kinds of needs of the elderly can be met, and the elderly can truly realize their old age and intelligent life. At present, in China, embedded smart elderly care services are in the primary stage, mainly with the government as the leading force, while other groups, such as social organizations, enterprises, citizens and so on, are not active enough to activate market vitality.

First of all, in the enterprise view, endowment is a huge investment, and payback period is longer, the risk is bigger, and embedded wisdom endowment is novelty, development operation is not yet mature, there is not enough technology, financial support, the government has not perfect policy support, profit is the main purpose of the enterprise development, in the face of such an uncertain things, enterprises do not have enough to participate [10]. Secondly, the main work of social organizations is to assist the government to carry out social services and other work. As an important part of social services, the power of social organizations cannot be ignored. However, at present, the government lacks policy support for social organizations regarding embedded smart pension service. Social organizations will face high operating costs in this pension service, resulting in their lack of enthusiasm to participate. 


\subsection{To Further Promote the Countermeasures Analysis of "Embedded" Intelligent Elderly Care Services}

\subsubsection{Strengthen the publicity of the new pension concept}

Since the traditional concept of pension is deeply rooted, in order to let people accept the new thing of embedded wisdom pension, we must strengthen the propaganda of the new concept of pension, update people's concept of pension. First, use the media to publicize and strengthen the concept of embedded intelligent endowment elaborate embedded wisdom endowment $\mathrm{AD}$, in the central plaza, LED screen, a TV, a short video, WeChat public number, weibo for propaganda, and there are many old people like to listen to the radio, read newspapers, you can also appeared in the traditional media to broadcast the content of the embedded intelligent endowment, combined with excellent examples, to transfer new endowment ideas, enhance the understanding of embedded intelligent endowment. Second, posters should be posted on community bulletin boards and bus stations, special lectures should be held in the community, brochures should be distributed, and intelligent equipment for elderly care should be displayed for people, so that people can truly feel its advantages. In order to improve people's cognition of embedded wisdom pension. Third, free viewing activities are organized. The community neighborhood committee will organize the elderly and their children to visit the embedded smart elderly care service center, hold free one-day service and intelligent product trial service, and let the elderly personally participate in it. Only when they truly experience its benefits, will they find its superiority. Fourth, special personnel should be arranged to popularize embedded wisdom pension knowledge in the community, and questionnaire survey should be conducted to understand people's acceptance degree, and targeted improvement should be made to the publicity method according to the situation of the century. In the survey, the elderly should also be asked for their opinions and suggestions on embedded wisdom for the aged, to understand their needs, and to form a benign publicity interaction.

\subsubsection{Intensify government efforts}

First of all, the government should give special policy support to the embedded smart pension, which is an important way to promote the development of smart pension, and also the best way to give confidence to social organizations and enterprises. The government should make a professional long-term plan for the embedded smart pension, and constantly encourage social organizations and enterprises to participate in the embedded smart pension service. Secondly, the government should strengthen financial support. It can provide special funds for the embedded smart pension, attract domestic and foreign investment, and provide tax preferential policies and welfare for enterprises that provide financial support for the embedded smart pension, so as to attract them to join in. Thirdly, the government can make tax reduction policies for the embedded smart pension service institutions to reduce their tax burden and enhance the development power of the pension service institutions with practical preferential policies. Finally, the government is committed to strengthening financial guidance. At all levels of government, it is necessary to increase the budget for embedded smart pension, so that the special funds can be used to achieve precise delivery. An embedded smart pension community investment fund can also be set up to fully attract social capital to the development of smart pension, encourage the cooperation between state-owned capital investment enterprises and pension institutions, let state-owned capital give full play to its role, and form a strong fund system with social capital.

\subsubsection{Optimize resource allocation}

The carrier of embedded smart pension is the community, and all services should be carried out based on the community. Therefore, under the leadership of the government, service resources can be attracted and integrated into the community to realize the optimal allocation of resources. First, strengthen the cooperation between community service main body, although different community service main job content is different, but their goals are consistent, all is in order to better service for the elderly pension, therefore, between different subjects can work together, in the wisdom of endowment service platform will use their own resources and idle is released, then will be to integrate these resources allocation, let every human, financial and material resources play its biggest role. Secondly, strengthen the training of volunteers, and make a special provision for volunteers to join the elderly care service. Only those who meet the requirements can enter the service. After entering the service, volunteers should be regularly arranged for training to learn nursing skills, safety knowledge and so on. Thirdly, medical institutions participating in the embedded smart pension should be equipped with specialized fixed medical personnel and equipment. Medical equipment prepared for the smart pension community should not be used for other purposes. The level of equipment equipped should be the same as that of medical institutions. Finally, strengthen the resources integration ability of the pension service platform, each old people have their own characteristics, demand is also each are not identical, wisdom endowment service platform to enhance data analysis ability, at the same time, the analysis of the old people need to be able to integrate various resources, 20, timely supply of various resources, so as to provide accurate and timely service for the aged. 


\subsubsection{We will strengthen social support}

Embedded intelligent pension service has various contents and requires a variety of participants, so it requires the joint efforts of all social forces. First of all, the enterprise is embedded wisdom endowment a important part of the service development, so to offer a great support for enterprises to participate in pension, catering, housekeeping service companies, in particular, is essential to the embedded wisdom pension services, in addition, health care, aged education institutions also need to give strong support, the parties should work together to enrich product supply types, giving full play to the advantages of resources in embedded wisdom pension services. Secondly, volunteers, charities and social organizations actively participate in embedded smart elderly care services, carry out public welfare activities, and give strong spiritual support to the elderly. Volunteers can make public speeches in Smart Elderly Community to provide warm services for the elderly. Charities can make donations for elderly people in need. Government departments should strengthen support for volunteers, organize professional training for them, institutionalize and standardize the development of volunteer elderly care services, and organize evaluation activities for outstanding participants to reward and commend them, so as to create a harmonious elderly care atmosphere.

\section{CONCLUSION}

Based on the case of Jinghua community for the aged, a study on the embedded smart nursing for the aged was conducted. The embedded smart nursing for the aged was known to be able to effectively alleviate the current situation of heavy burden and lack of nursing function caused by the change of family structure, besides, it provides both physiological and psychological nursing for the aged and improves the life of the aged in a comprehensive way. However, due to the fact that our country' $\mathrm{s}$ development in the embedded smart nursing for the aged is still in its early stage, there are many problems concerning this area at present. In addition, many factors such as the impediment of the traditional idea of nursing for the aged, the lack of government encouragement, low quality of embedded social resources, insufficient integration of social forces have all played a negative role in the development of embedded smart nursing for the aged, making it achieve little and slow progress these years.Based on the research, it is suggested that propaganda of the new idea of nursing for the aged should be enhanced, and government should strengthen its promotion role in this area, optimize the resource distribution and give full play to the various social forces. It is the sincere hope of this paper that all the old people can have physical and psychological security and support, and furthermore, live a happy life with spiritual enjoyment and sustenance as well.

\section{REFERENCES}

[1] Yang Yansui.Silver Economy and Embedded Elderly Service [M]. Tsinghua University Press, 2017.

[2] Wang Hongyu, Wang Xiaoyu.The Trinity of Conservation and Medicine: Research on Home Elderly Service System in Smart Community [J] Journal of Wuhan University (Philosophy and Social Sciences Edition), 2018, 71 (04):156-168

[3] Huang Jianfeng, Zhang Xiaoyi.Research on China's smart pension industry policy -- based on policy tools and technology roadmap model [J] China Science and Technology Forum, 2020(01):69-79

[4] Wang Yue. Thinking on the Multiple Collaborative Participation of Medical Care Combined with Elderly Care Services [N] China Population Journal, 2020-0221(003)

[5] Liu Weiyi. Development Status of Smart Elderly Care in Foreign Countries and Enlightenment to China [J]. China Collective Economy, 2019(07):166-168.

[6] Wen Jing. The model of pension service in Japan and its experience and lessons [J]. Special Zone Economy, 2020(01):86-89.

[7] He Yuanyuan. Research on the Existing Problems and Countermeasures of "Smart Elderly Care" in China -- Based on the Investigation of Jinan [D]. Jinan: Shandong University, 2019.

[8] Su Xiang. Research on Practice, Predictions and Development of "Embedded" Intelligent Elderly Service [D]. East China University of Science and Technology, 2019.

[9] Che Xiaoduan. Promoting the work of "smart pension" to explore new ways for China's pension [J]. China National People's Congress, 2016, (15).

[10] Qin Feng, Ding Fuxing. Effective docking between demand and supply of smart pension in Suzhou [J]. Contemporary Economy, 2018, (1). 